\title{
Pengambilan Keputusan dan Preferensi Petani Menggunakan Pupuk Subsidi di Kecamatan Sentra Padi Kabupaten Timor Tengah Utara (Studi Kasus Kecamatan Biboki Anleu)
}

${ }^{1}$ Simon Juan Kune, ${ }^{1}$ Agustinus Nubatonis, ${ }^{*}$ Boanerges Putra Sipayung, ${ }^{1}$ Yohanes P.V Mambur

${ }^{1}$ Program Studi Agribisnis, Fakultas Pertanian Universitas Timor Kabupaten Timor Tengah Utara.

*Corespondence author: sipayung.boanerges@gmail.com

\section{Article Info}

Article history:

Received 17 October 2021

Received in revised from 17 October 2021

Accepted 13 November 2021

DOI: https://doi.org/10.32938/ag.v6i4.1497

\section{Keywords:}

Border Area

Farmer's Decision

Food

Preference

Subsidy of Fertilizer

\begin{abstract}
Abstrak
Subsidized fertilizer is one of the policies carried out by the government to increase agricultural production, especially food crops. This study aims to analyze the decision making of farmers to buy and use subsidized fertilizers, as well as the preferences of farmers in Biboki Anleu Subdistrict to use subsidized fertilizers. The research was carried out in May-July 2021. Quantitative description methods and logistic regression were used to analyze this study. The number of samples used in this study amounted to 320 respondents. The results of this study are the area of land, the performance of the extension worker, knowledge, the amount of production affect the decision of farmers to buy subsidized fertilizer. Farmers' decision-making to use subsidized fertilizers is significantly influenced by land area, extension staff's performance, knowledge, and ability to access information. The opinion and performance of the extension worker, land area, ability to access information and purchase fertilizer at official kiosks are the preferences of lowland rice farmers.
\end{abstract}

\section{Pendahuluan}

Pertanian merupakan sektor penting bagi Indonesia. Sektor pertanian merupakan salah satu penopang perekonomian Indonesia. Kontribusi sektor pertanian terhadap Produk Domestik Bruto (PDB) Indonesia pada tahun 2017-2019 berada pada kisaran 10-11\%. Pada masa pandemic kontribusi sektor pertanian meningkat mencapai $15 \%$ pada triwulan ke II pada tahun 2021. Masa pandemi Covid19, sektor pertanian masih dapat bertumbuh positif dimana sektorsektor lainnya menurun (Badan Pusat Statistik, 2021). Selain sebagai penopang perekonomian, sektor pertanian berhubungan dengan ketahanan pangan masyarakat Indonesia. Perwujudan dari ketahanan pangan terjadi apabila tersedia pangan yang cukup dan merata, dan masyarakat Indonesia memiliki akses ekonomi dan fisik terhadap kebutuhan pangan yang bertujuan memenuhi gizi (Dewan Ketahanan Pangan, 2007).

Pertumbuhan jumlah penduduk dari tahun 2010-2020 rata-rata sebesar $1.25 \%$ per tahun atau sekitar 3,2 juta jiwa per tahun (Badan Pusat Statistik, 2020). Hal ini akan berdampak dengan peningkatan terhadap permintaan pangan. Permintaan pangan meningkat lebih cepat dari kemampuan menyediakan pangan. Arah kebijakan yang harus ditempuh dengan peningkatan kapasitas produksi nasional (Dewan Ketahanan Pangan, 2007). Peningkatan kapasitas produksi dapat dilakukan dengan ekstensifikasi dan intensifikasi pertanian. Intensifikasi pertanian bertujuan untuk meningkatkan produktivitas lahan pertanian. Peningkatan produktivitas dapat dilakukan dengan pemupukan. Pemupukan berpengaruh positif terhadap peningkatan produktivitas lahan (Ambarita dan Kartika, 2015).

Kebijakan yang dilakukan oleh pemerintah dalam meningkatkan produktivitas dan produksi pangan di Indonesia dengan memberikan subsidi pupuk. Pemberian subsidi terhadap berbagai jenis pupuk kimia diberikan pemerintah bertujuan meningkatkan produksi khususnya komoditas tanaman pangan dan membantu petani mengakses pupuk dengan harga yang terjangkau (Darwis dan Supriyati, 2013).

Tabel 1. Realisasi Subsidi Pupuk Dan Produksi Padi Indonesia

\begin{tabular}{cccc}
\hline Tahun & $\begin{array}{c}\text { Realisasi Subsidi Pupuk } \\
\text { (triliun Rupiah) }\end{array}$ & Produksi Padi (ton) & $\begin{array}{c}\text { Produktivitas } \\
\text { (Ton/Ha) }\end{array}$ \\
\hline 2018 & 33,6 & $59.199 .392,89$ & 5,92 \\
2019 & 37,1 & $54.607 .277,43$ & 5,33 \\
2020 & 26,6 & 54.650 .506 & 5,41 \\
\hline
\end{tabular}

Sumber: Kementerian Keuangan dan Badan Pusat Statistik diolah tahun 2021

Realisasi subsidi pupuk meningkat sampai tahun 2019 tetapi menurun di tahun 2020 yang diakibatkan pandemic Covid19. Produksi menurun dari tahun 2018 ke tahun 2019, lalu meningkat pada tahun 2020. Padahal realisasi subsidi pupuk tahun 2020 menurun hampir 30\% dibandingkan di tahun 2019. 
Kabupaten Timor Tengah Utara merupakan salah satu kabupaten terluar yang berbatasan dengan Negara Timor Leste tepatnya dengan Distrik Oekusi. Kebijakan pangan pada wilayah perbatasan merupakan hal penting karena masyarakat perbatasan mayoritas bermata pencaharian sebagai petani. Ketahanan pangan merupakan hal yang penting pada wilayah perbatasan sebagai motivasi dan kemauan mempertahankan idealisme dan ideologi Negara Indonesia (Christyanto \& Mayulu, 2021).

Kabupaten Timor Tengah Utara memiliki lahan sawah seluas 7489 ha yang $30 \%$ berada pada kecamatan Biboki Anleu. Kecamatan Biboki Anleu memiliki lahan sawah sebesar 2779 ha yang telah merupakan sawah irigasi teknis (Badan Pusat Statistik, 2021a). Rata-rata produktivitas lahan di Kecamatan Biboki Anleu yang merupakan salah satu daerah sentra padi di Kabupaten Timor Tengah Utara sebesar 3,797 ton/ha (Badan Pusat Statistik, 2021a). Produktivitas sawah pada sentra padi di Kabupaten Timor Tengah Utara jauh lebih kecil jika dibandingkan rata-rata produktivitas lahan sawah di Indonesia.

Penggunaan pupuk dengan dosis yang tepat seharusnya berimplikasi dengan peningkatan produktivitas sawah yang ada di Kecamatan Biboki Anleu. Penggunaan pupuk pada tingkat petani seringkali tidak sesuai dengan dosis anjuran dari pemerintah. Petani hanya mengandalkan perasaan dan pengalaman seadanya dalam menggunakan pupuk. Siallagan et al., (2014), bahwa petani di Kabupaten Serdang Begadai mengaplikasikan pupuk bersubsidi seringkali lebih dari dosis anjuran pemerintah.

Penggunaan pupuk kimia lebih dari dosis anjuran dan berlangsung dalam waktu yang lama akan mengakibatkan perubahan fisik tanah dan meninggalkan residu sehingga menurunkan produktivitas lahan (Allo, 2016). Penurunan dari produktivitas lahan mengakibatkan petani ragu dalam menggunakan pupuk bersubsidi. Petani beranggapan bahwa pupuk anorganik yang menyebabkan penurunan hasil panen. Petani juga seringkali terpengaruh akan pendapat orang lain yang belum pasti kebenarannya. (Widiyanti ,2016), petani menggunakan pupuk berdasarkan saran dan pengaruh orang yang terdekat dengannya. Orang terdekat dengan petani, baik itu keluarga, tetangga ataupun penyuluh pertanian menjadi referensi bagi petani tersebut (Dwiastuti et al., 2010). Penelitian ini bertujuan untuk menganalisis sikap petani padi sawah dalam membuat keputusan untuk membeli dan menggunakan pupuk bersubsidi dan preferensi petani dalam menggunakan pupuk bersubsidi di Kecamatan Biboki Anleu yang merupakan salah satu sentra penghasil padi di Kabupaten Timor Tengah Utara.

\section{Metode Penelitian}

\section{Jenis Data, Lokasi Penelitian, Dan Jumlah Sampel}

Data yang digunakan dalam penelitian ini adalah data primer dan data sekunder. Data primer diperoleh melalui metode observasi dan wawancara. Data sekunder diperoleh dari Kementerian Keuangan Republik Indonesia dan Badan Pusat Statistik. Penelitian ini dilaksanakan pada bulan Mei-Juli 2021 di Kecamatan Biboki Anleu. Responden dalam penelitian ini adalah petani padi sawah yang berdomisili dan mempunyai lahan sawah di Kecamatan Biboki Anleu. Populasi petani di Kecamatan Biboki Anleu sebesar 4.060. Sampel penelitian ini diambil berdasarkan tabel Isaac dan Michael dengan taraf $a=5 \%$ sebesar 320 responden petani padi sawah.

\section{Analisis Data}

Penelitian ini menganalisis pengambilan keputusan petani untuk membeli dan penggunaan pupuk bersubsidi menggunakan regresi logistik dengan software SPSS.22. Untuk menganalisis preferensi petani dalam penggunaan pupuk menggunakan metode deskriptif kuantitatif. Model yang digunakan menganalisis keputusan petani membeli pupuk bersubsidi meruju pada (Juanda, 2009):

Logit dari model yang digunakan:

$$
\widehat{Y}_{1}=P\left(\underline{X}_{i}\right)=\frac{1}{1+e^{-\left(\beta_{0}+\beta_{1} X_{1}+\cdots \beta_{n} X_{n}\right)}}
$$

$g\left(X_{i}\right)=\ln \frac{P \underline{X_{i}}}{1-P\left(\underline{X_{i}}\right)}=\beta_{0}+\beta_{1}$ L.lahan $+\beta_{2}$ Exp $+\beta_{3}$ Pengetahuan $+\beta_{4}$ K. Penyuluh $+\beta_{5}$ produksi $+e$ Keterangan:

$\mathrm{P}$

Peubah peluang atau proporsi membeli pupt

= Luas lahan persawahan yang dimiliki oleh petani responden

$\operatorname{Exp} \quad=$ Pengalaman berusahatani petani responden

Pengetahuan = Pengetahuan petani responden mengenai penyaluran pupuk bersubsidi.

K.Penyuluh = Kinerja penyuluh dalam membantu petani responden mendapatkan pupuk bersubsidi

Produksi = Produksi padi sawah 1 kali tanam . 
Model yang digunakan menganalisis keputusan petani dalam menggunakan pupuk bersubsidi merujuk pada model (Juanda, 2009):

Logit dari model yang digunakan:

$$
\begin{gathered}
g\left(X_{i}\right)=\ln \frac{P \underline{X_{i}}}{1-P\left(\underline{X_{i}}\right)}=\beta_{0}+\beta_{1} \text { L. Lahan }+\beta_{2} \text { A. Informasi }+\beta_{3} \text { Pengetahuan }+\beta_{4} K . \text { Penyuluh }+\beta_{5} D P P+ \\
\beta_{6} \text { Produksi }+e
\end{gathered}
$$

Keterangan :

$\mathrm{P}$

Peubah peluang atau proporsi menggunakan pupuk bersubsidi

L.Lahan = Luas lahan persawahan yang dimiliki oleh petani responden

A.Informasi $=$ Kemampuan petani responden di Kecamatan Biboki Anleu mengakses informasi

dan internet

Pengetahuan = Pengetahuan petani responden mengenai penggunaan pupuk bersubsidi

K.Penyuluh = Kinerja penyuluh membantu petani responden menggunakan pupuk bersubsidi

DPP = peubah boneka pembelian pupuk bersubsidi $(D=1$ membeli pupuk bersubsidi di kios pengecer resmi, $\mathrm{D}=0$ tidak membeli pupuk bersubsidi di kios pengecer resmi)

Produksi = Jumlah produksi padi sawah dalam periode 1 kali tanam .

\section{Hasil dan Pembahasan}

\section{Karekteristik Demografi Responden Di Kecamatan Biboki Anleu}

Di dalam penelitian ini menggunakan jumlah tanggungan keluarga, pendidikan, dan usia responden sebagai karakteristik demografi responden. Karakteristik demografi petani responden dapat dilihat pada Tabel 2.

Tabel 2. Karakteristik Responden Petani di Kecamatan Biboki Anleu

\begin{tabular}{lccc}
\hline Karakteristik Demografi & Tingkatan & Jumlah responden (Jiwa) & Persentase (\%) \\
\hline \multirow{2}{*}{ Lama pendidikan (tahun) } & $6 \leq$ & 265 & 81.8 \\
\hline \multirow{2}{*}{ Tanggungan keluarga (jiwa) } & $7-12$ & 59 & 18.2 \\
\hline \multirow{3}{*}{ Usia (Tahun) } & $4 \leq$ & 181 & 55.8 \\
& 25 & 143 & 44.2 \\
\hline
\end{tabular}

Sumber: Data Primer diolah tahun 2021

Berdasarkan Tabel 2 pendidikan petani responden dominan mendapat pendidikan pada tingkatan sekolah dasar. Petani responden didominasi dengan usia di atas 50 tahun. Usia yang memasuki masa pensiun akan menurunkan produktivitas dalam usahatani. Petani yang berkarakteristik pendidikan yang rendah dan usia yang memasuki masa pensiun memiliki kendala untuk mengakses informasi maupun teknologi. Petani yang berpendidikan rendah sulit untuk mengakses informasi dan pengetahuan melalui internet (Damanik \& Meilvis, 2020).

\section{Faktor Yang Mempengaruhi Keputusan Petani Untuk Membeli Pupuk Bersubsidi Di Kecamatan Biboki Anleu}

Pembelian pupuk bersubsidi merupakan salah satu proses yang harus dilakukan oleh petani sebelum menggunakan pupuk bersubsidi di Kecamatan Biboki Anleu. Hasil analisis faktor yang mempengaruhi petani di Kecamatan Biboki Anleu dalam pengambilan keputusan petani responden dapat dilihat pada Tabel 3.

Tabel 3. Analisis Faktor Yang Mempengaruhi Petani Membeli Pupuk Bersubsidi Di Kecamatan

\begin{tabular}{|c|c|c|c|c|}
\hline Variabel & $\mathrm{B}$ & S.E. & Sig. & OddRatio \\
\hline Luaslahan & 0.558 & 0.236 & $0.018^{a}$ & 1.748 \\
\hline Exp & 0.103 & 0.252 & 0.684 & 1.108 \\
\hline Pengetahuan & -0.969 & 0.561 & $0.084 \mathrm{~b}$ & 0.379 \\
\hline Kpenyuluh & 1.001 & 0.561 & $0.074 \mathrm{~b}$ & 2.721 \\
\hline Jumlahproduksi & -0.539 & 0.270 & $0.046^{a}$ & 0.584 \\
\hline Constant & -0.399 & 1.837 & 0.828 & 0.671 \\
\hline \multicolumn{5}{|c|}{ Chi-Square } \\
\hline Hosmer And Lameshow Test & 4.803 & & 0.778 & \\
\hline Omnibus test & 16.137 & & 0.006 & \\
\hline Nagelkerke R Square & & 0.40 & & \\
\hline
\end{tabular}
Biboki Anleu 
Ketepatan model dapat dilihat dengan nilai Nagelkerke R Square. Nilai ini menjelaskan bahwa kemampuan variabel independen berpengaruh terhadap variabel dependen. Nilai Nagelkerke R Square sebesar 0.40 menunjukkan bahwa variabel indenpenden menjelaskan $40 \%$ terhadap variabel dependen. Sisanya 60\% dijelaskan oleh variabel di luar model yang digunakan. Untuk menguji kebaikan model menggunakan nilai dari Hosmer dan Lemeshow. Nilai Hosmer dan Lemeshow sebesar 4.803 dengan signifikansi 0.778. Nilai signifikansi lebih besar dari $a=$ 0.05. Nilai Omnibus test sebesar 16.137 dan signifikan pada $a=0.05$. Hal ini berarti variabel independen yang digunakan dalam model ini berpengaruh terhadap variabel dependen. Dapat disimpulkan model yang digunakan layak untuk memprediksi keputusan petani dalam membeli pupuk bersubsidi di Kecamatan Biboki Anleu.

a. Luas Lahan

Luas lahan berpengaruh signifikan pada $a=5 \%$ terhadap pembelian pupuk bersubsidi. Petani yang memiliki luas lahan lebih besar memiliki peluang sebesar 1,748 kali membeli pupuk bersubsidi dibandingkan dengan petani padi sawah yang memiliki luas lahan sempit. Petani yang berhak membeli pupuk bersubsidi memiliki luas lahan maksimal dua hektar. Petani yang memiliki lahan yang lebih luas lebih cenderung untuk mencari kepastian dan membuat persiapan mengenai usahataninya. Pinem \& Pratiwi (2020), luas lahan berpengaruh terhadap keputusan petani untuk membeli benih bersertifikat untuk digunakan dalam usahatani kelapa sawit di Kabupaten Asahan.

b. Kinerja Penyuluh

Kinerja penyuluh di Kecamatan Biboki Anleu dalam melayani petani responden mengenai pupuk bersubsidi berpengaruh signifikan pada $a=10 \%$ terhadap keputusan pembelian pupuk bersubsidi sebesar 2.721 kali jika dibandingkan dengan penyuluh yang kurang aktif atau kinerja rendah. Penyuluh bersama dengan kelompok tani menyusun RDKK sesuai dengan luas lahan petani responden. Persepsi petani responden terhadap kinerja penyuluh pertanian cukup puas mengenai informasi ketersediaan pupuk bersubsidi. Ketersediaan pupuk di Kecamatan Biboki Anleu sesuai dengan perencanaan yang disusun melalui RDKK. Hal ini sejalan dengan Andajani \& Pratama (2017), pelayanan yang dilakukan penyuluh pertanian mengenai penanganan pupuk bersubsidi memberikan kepuasan kepada petani bawang merah di Kabupaten Nganjuk.

c. Pengetahuan Penyaluran Pupuk Bersubsidi (6 Tepat)

Pengetahuan yang dimiliki petani padi sawah yang menjadi responden berpengaruh signifikan pada $a=10 \%$ terhadap keputusan untuk membeli pupuk bersubsidi. Pengetahuan yang dimiliki petani responden mengenai jumlah pupuk yang dialokasikan, kios pembelian, dan ketersediaan pupuk meningkatkan peluang untuk membeli pupuk bersubsidi sebesar 0.379 kali dibandingkan jika petani responden tidak memiliki pengetahuan mengenai penyaluran pupuk bersubsidi. Pengetahuan tentang ketersediaan pupuk dan tempat dapat dibelinya pupuk bersubsidi mempengaruhi petani untuk membeli pupuk bersubsidi tersebut. Hal ini sesuai dengan Aqmala \& Novianti (2017), pengetahuan meningkatkan keputusan konsumen untuk membeli produk organik.

d. Jumlah produksi

Jumlah produksi padi yang dihasilkan berpengaruh signifikan pada $a=5 \%$ terhadap keputusan petani untuk membeli pupuk bersubsidi. Petani responden memiliki harapan untuk memperoleh hasil panen yang maksimal dari usahatani mereka. Jumlah produksi meningkatkan peluang petani untuk membeli pupuk sebesar 0.584 kali jika dibandingkan dengan petani yang memiliki produksi lebih sedikit. Petani responden memiliki kepercayaan bahwa dalam usahataninya khususnya padi sawah, mereka membutuhkan pupuk bersubsidi untuk meningkatkan hasil panennya. Sesuai dengan Permana et al., (2018), faktor kemauan, pengetahuan, kebiasaan, serta motif ekonomi mempengaruhi pengambilan keputusan yang dilakukan oleh petani di Kabupaten BatangHari untuk mengelola lahan rawa menjadi lahan sawah.

\section{Faktor Yang Mempengaruhi Petani Padi Sawah Di Kecamatan Biboki Anleu Menggunakan Pupuk Bersubsidi.}

Variabel yang digunakan dalam menganailisis keputusan petani menggunakan pupuk bersubsidi adalah luas lahan, kemampuan mengakses informasi, pengetahuan penggunaan pupuk, kinerja penyuluh pertanian, membeli pupuk bersubsidi atau tidak dan jumlah produksi per periode tanam. Hasil analisis keputusan petani dalam menggunakan pupuk bersubsidi dapat dilihat pada Tabel 4. 
Tabel 4. Hasil Analisis Faktor Yang Mempengaruhi Keputusan Petani Padi Sawah Menggunakan Pupuk Bersubsidi di Kecamatan Biboki Anleu

\begin{tabular}{lcccc}
\hline Variabel & B & S.E & Sig & OddRatio \\
\hline Luaslahan & 0.658 & 0.291 & $0.024 \mathrm{~b}$ & 1.932 \\
Kpenyuluh & 3.043 & 0.719 & $0.000^{\mathrm{a}}$ & 20.961 \\
Belipupuk & 0.854 & 0.341 & $0.012^{\mathrm{b}}$ & 2.350 \\
PengetahuanGP & 1.732 & 0.861 & $0.044 \mathrm{~b}$ & 5.651 \\
AksesInformasi & 1.554 & 0.733 & $0.034 \mathrm{~b}$ & 4.729 \\
Jumlahproduksi & 0.171 & 0.298 & 0.567 & 1.186 \\
Constant & -19.939 & 3.449 & 0.000 & 0.000 \\
\hline & Chi-square & & 0.080 & \\
\hline Hosmer dan Lemeshow Test & 14.052 & & & \\
Omnimbus test & 140.751 & 0.000 & \\
\hline Nagelkerke R Square & & & \\
\hline
\end{tabular}

Sumber: Data Primer diolah tahun 2021. Keterangan a dan $b$ signifikan pada $a=1 \%$ dan $5 \%$.

Ketepatan model dapat dilihat dengan nilai Nagelkerke R Square. Nilai ini menjelaskan bahwa kemampuan variabel independen berpengaruh terhadap variabel dependen. Nilai Nagelkerke R Square sebesar 0.48 menunjukkan bahwa variabel indenpenden menjelaskan $48 \%$ terhadap variabel dependen. Sisanya 52\% dijelaskan oleh variabel di luar model yang digunakan. Untuk menguji kebaikan model menggunakan nilai dari Hosmer dan Lemeshow. Nilai Hosmer dan Lemeshow sebesar 14.052 dengan signifikansi 0.08. Nilai signifikansi lebih besar dari $\mathrm{a}=$ 0.05. Nilai Omnibus test sebesar 140.751 dan signifikan pada $a=0.05$. Hal ini berarti variabel independen yang digunakan dalam model ini berpengaruh terhadap variabel dependen. Dapat disimpulkan model yang digunakan layak untuk memprediksi keputusan petani dalam menggunakan pupuk bersubsidi di Kecamatan Biboki Anleu.

a. Luas Lahan

Luas lahan berpengaruh signifikan terhadap keputusan petani menggunakan pupuk bersubsidi di Kecamatan Biboki Anleu pada $a=5 \%$. Lahan yang semakin luas meningkatkan kemungkinan petani padi sawah di Kecamatan Biboki Anleu menggunakan pupuk bersubsidi sebesar 1.932 kali jika dibandingkan petani padi sawah yang memiliki lahan yang lebih sempit. Semakin luas lahan yang dimiliki petani, akan semakin besar juga biaya yang akan dikeluarkan untuk pemupukan (Mamondol \& Sabe, 2016). Harga pupuk bersubsidi jauh lebih murah jika dibandingkan dengan harga pupuk non subsidi. Petani di Kecamatan Biboki Anleu akan memilih untuk menggunakan pupuk bersubsidi jika dibandingkan pupuk non subsidi, tujuannya untuk menghemat biaya usahatani yang akan dikeluarkan. Petani dengan luas lahan akan membuat keputusan terhadap pemilihan input pertanian yang digunakan, hal ini sejalan dengan Nasution \& Wardana (2020), luas lahan berpengaruh terhadap keputusan petani sawit untuk memilih bibit varietas tenera di perkebunan kelapa sawit.

b. Kinerja Penyuluh

Kinerja penyuluh pertanian yang bertugas di Kecamatan Biboki Anleu berpengaruh signifikan terhadap petani responden dalam memutuskan untuk menggunakan pupuk bersubsidi pada $\mathrm{a}=1 \%$. Kinerja penyuluh baik meningkatkan peluang petani untuk memutuskan menggunakan pupuk bersubsidi sebesar 20.961 kali jika dibandingkan penyuluh pertaniannya yang kurang aktif atau berkinerja kurang. Pelayanan yang baik jika dilakukan oleh penyuluh pertanian akan memotivasi petani untuk mencontoh hal yang dilakukan penyuluh pertanian tersebut. Penyuluh pertanian merupakan sebagai salah satu sumber informasi yang dapat dipercaya oleh petani. Pemilihan dan penggunaan input pertanian akan dipengaruhi oleh intensitas interaksi penyuluh pertanian dengan petani (Descartes et al., 2021). Pada Kabupaten Cianjur dan Garut, penyuluh berperan dalam mempengaruhi keputusan petani untuk mengadopsi teknologi dalam usahataninya (Indraningsih, 2016).

c. Pembelian Pupuk Bersubsidi di Kios Pengecer Resmi

Pembelian pupuk bersubsidi di kios pengecer resmi berpengaruh signifikan terhadap peluang keputusan petani untuk menggunakan pupuk bersubsidi pada $a=5 \%$. Pembelian pupuk bersubsidi pada kios pengecer resmi meningkatkan peluang penggunaan pupuk bersubsidi petani padi sawah di Kecamatan Biboki Anleu sebesar 2.350 kali jika dibandingkan petani yang tidak membeli pupuk di kios pengecer resmi.

Petani yang membeli di kios pengecer pastinya mendapatkan harga lebih murah, kualitas terjaga, serta kepercayaan terhadap kios pengecer bahwa pengecer menjual barang yang asli lebih baik daripada yang bukan pengecer resmi. Kepastian terhadap harga, kualitas, dan kepercayaan meningkatkan keputusan petani menggunakan pupuk bersubsidi pada usahataninya. Hal ini sejalan dengan Hakim \& Saragih (2019), persepsi harga, kualitas dan citra 
merk meningkatkan keputusan konsumen untuk membeli pupuk NPK Mutiara di Pulau Batam pada toko UD.Barelang Tani Jaya.

d. Pengetahuan Menggunakan Pupuk

Pengetahuan menggunakan pupuk mempengaruhi keputusan petani secara signifikan pada $a=5 \%$. Petani yang mempunyai pengetahuan menggunakan pupuk berpeluang menggunakan pupuk bersubsidi sebesar 5.651 kali jika dibandingkan petani memiliki pengetahuan yang kurang mengenai penggunaan pupuk dengan tepat. Petani responden yang memiliki pengetahuan yang baik mengerti pentingnya pupuk sebagai salah satu instrumen yang bertujuan untuk meningkatkan produksi dan produktivitas lahan sawah. Petani di Kecamatan Biboki Anleu yang memiliki pengetahuan yang baik mengenai penggunaan salah satu input pertanian atau program yang direncanakan pemerintah, cenderung lebih menerima. Hal ini sejalan dengan Prasetyo et al., (2019), bahwa petani padi sawah di Kabupaten Indramayu yang memiliki pengetahuan yang lebih baik cenderung lebih mengikuti program yang direncanakan pemerintah. e. Akses Informasi

Kemampuan yang dimiliki petani padi sawah dalam mengakses informasi/internet berpengaruh signifikan terhadap keputusan petani untuk menggunakan pupuk bersubsidi di Kecamatan Biboki Anleu pada $a=5 \%$. Kemampuan mengakses informasi/internet meningkatkan peluang penggunaan pupuk bersubsidi sebesar 4.729 kali jika dibandingkan dengan petani yang kurang memiliki kemampuan dalam mengakses informasi.

Petani di Kecamatan Biboki Anleu yang berkemampuan mengakses informasi/internet lebih baik akan memiliki referensi yang lebih dalam menggunakan pupuk. Referensi yang didapatkan menunjang kreativitas petani dalam berusahatani padi sawah. Hal ini sejalan dengan Setiawati (2016) \& Andriani et al., (2018), petani yang memiliki kemampuan untuk mengakses informasi dari internet memiliki referensi lebih banyak jika dibandingkan dengan petani yang memiliki kemampuan yang kurang dalam mengakses internet.

\section{Preferensi Petani Padi Sawah Menggunakan Pupuk Bersubsidi di Kecamatan Biboki Anleu}

Pupuk merupakan salah satu input pertanian penting yang bertujuan meningkatkan produktivitas lahan. Pemerintah memberikan subsidi pupuk kepada petani tanaman pangan khususnya petani padi sawah bertujuan meningkatkan produksi pangan untuk menunjang ketahanan pangan nasional. Proses penggunaan pupuk bersubsidi dianalisis dalam dua proses yaitu proses pembelian dan proses penggunaan pupuk itu sendiri.

Petani yang menjadi responden mayoritas berpendidikan rendah, berpengalaman tinggi dan hampir memasuki masa usia pensiun. Petani yang berpendidikan rendah dan berpengalaman tinggi akan sulit untuk mengubah pola pikir mengenai manajemen usahataninya, karena usahatani yang mereka kerjakan merupakan cara mereka bertahan hidup yang sudah dilakukan secara berulang. Mayoritas petani dengan karakteristik seperti ini memiliki kompetensi yang sangat rendah dan tidak mampu mengambil keputusan (Simamora, 2020).

Proses pembelian di kios pengecer resmi pupuk bersubsidi oleh petani dapat dilakukan jika elektronik-rencana definitif kebutuhan kelompok (e-RDKK) telah disusun. Perencanaan e-RDKK dilakukan bersama dengan penyuluh pertanian pada tahun sebelumnya dan ditinjau berdasarkan luas lahan yang dimiliki petani dengan syarat maksimal 2 hektar. Kenyataan di lapangan seringnya penyuluh pertanian menyusun sendiri e-RDKK berdasarkan data luas lahan yang dimiliki petani bukan rencana luas lahan yang akan diusahakan petani. Kuota pupuk bersubsidi petani di Kecamatan Biboki Anleu sangat bergantung dengan kinerja penyuluh pertanian. Penyuluh pertanian juga menjadi sumber informasi mengenai waktu tersedianya pupuk dan ketersediaan pupuk di kios pengecer resmi. Kebergantungan terhadap penyuluh mempengaruhi kinerja petani dalam berusaha tani (Tahoni \& Mambur, 2020). Resiko yang dihadapi petani jika terlalu bergantung kepada penyuluh pertanian, maka petani tidak mampu mempersiapkan pembiayaan pembelian pupuk karena penyuluh belum tentu mengetahui rencana luas lahan yang akan diusahakan oleh petani. Hal ini mengakibatkan pupuk yang dibeli dalam berusahatani padi sawah di Kecamatan Biboki Anleu tidak sesuai dengan kuota yang telah direncanakan pada e-RDKK.

Penyuluh pertanian merupakan ujung tombak yang membawa perubahan bagi pertanian. Beberapa dari penyuluh pertanian memiliki usahatani di Kecamatan Biboki Anleu maupun kecamatan tetangga. Petani sering mencontoh yang dilakukan oleh penyuluh dalam berusahatani termasuk dalam penggunaan pupuk. Tahoni \& Mambur (2020), penyuluh memiliki peran sebagai motivator terhadap petani untuk meningkatkan kinerja petani yang bertujuan memaksimalkan produksi usahataninya.

Permasalahan distribusi pupuk bersubsidi yang sering dijumpai di lapangan bahwa ketersediaan pupuk seringkali tidak sesuai dengan masa tanam (Azis, 2016). Pengetahuan mengenai alur distribusi, penggunaan pupuk dan kemampuan petani memperoleh informasi baik 
dari penyuluh, kios pengecer, dan internet membantu petani untuk mempersiapkan biaya untuk pembelian pupuk bersubsidi. Mayoritas petani dengan luas lahan yang luas memiliki persiapan yang lebih baik mengenai pembiayaan terhadap pembelian pupuk bersubsidi. Selain itu, petani yang memiliki luas lahan yang lebih luas juga ingin memiliki kepastian yang berhubungan dengan ketersediaan pupuk bersubsidi. Luas lahan semakin luas, akan semakin besar juga biaya dikeluarkan dan jumlah pupuk yang akan digunakan.

Produksi padi yang diharapkan pada lahan persawahan seringkali berdasarkan jumlah produksi masa tanam sebelumnya. Hal ini sering dilakukan oleh petani yang berpengalaman tinggi dan pendidikan rendah. Pengulangan hal yang sama pada setiap musim tanam petani mengakibatkan semua input pertanian yang dipersiapkan akan sama dengan musim tanam sebelumnya. Kemampuan manajemen yang masih rendah dan orientasi bisnis yang rendah masih terlihat pada petani di Kabupaten Timor Tengah Utara (Sipayung \& Joka, 2021).

\section{Simpulan}

Faktor luas lahan, kinerja penyuluh, pengetahuan, dan ekspektasi terhadap jumlah produksi yang sama dengan musim tanam sebelumnya berpengaruh signifikan terhadap keputusan petani untuk membeli pupuk bersubsidi. Faktor luas lahan, kinerja penyuluh, pengetahuan, membeli di kios resmi, serta kemampuan mengakses informasi baik dari penyuluh dan internet berpengaruh signifikan terhadap keputusan petani untuk menggunakan pupuk bersubsidi.

Preferensi petani padi sawah di Kecamatan Biboki Anleu untuk menggunakan pupuk bersubsidi merupakan luas lahan yang dimiliki petani, pendapat ataupun hasil kinerja dari penyuluh pertanian, kemampuan mengakses informasi dan membeli pupuk bersubsidi di kios resmi.

\section{Ucapan Terima Kasih}

Penulis mengucapkan terima kasih kepada Lembaga Penelitian dan Pengabdian Kepada Masyarakat Universitas Timor dan Pusat Studi Lahan Kering yang telah membantu penyelesaian penelitian dengan memberikan bantuan dana melalui skema pendanaan Penelitian Pusat Studi Lahan Kering dengan nomor: 07/UN60/LPPM/PP/2021.

\section{Pustaka}

Allo, M. K. (2016). Kondisi Sifat Fisik dan Kimia Tanah pada Bekas Tambang Nikel serta Pengaruhnya terhadap Pertumbuhan Trengguli dan Mahoni. Jurnal Hutan Tropis, 4(2).

Ambarita, J. P., \& Kartika, I. N. (2015). Pengaruh Luas Lahan, Penggunaan Pestisida, Tenaga Kerja, Pupuk Terhadap Produksi Kopi Di Kecamatan Pekutatan Kabupaten Jembrana. EJurnal EP Unud, 4(7).

Andajani, W., \& Pratama, A. C. (2017). Analisis Kepuasan Petani Bawang Merah (Allium ascolonicum, L) terhadap Kinerja Pelayanan PPL dan Penanganan Pupuk Bersubsidi. Agrinika, 1(1). https://doi.org/dx.doi.org/10.30737/agrinika.v1i1.307

Andriani, R., Kusumo, B., Rasmikayati, E., Mukti, G. W., Fatimah, S., \& Saefudin, B. R. (2018). Faktor-Faktor Yang Mempengaruhi Keputusan Petani Mangga Dalam Menggunakan Teknologi Off Season Di Kabupaten Cirebon. MIMBAR AGRIBISNIS: Jurnal Pemikiran Masyarakat Ilmiah Berwawasan Agribisnis, 4(1), 57-69. https://doi.org/http://dx.doi.org/10.25157/ma.v4i1.789

Aqmala, D., \& Novianti, A. (2017). Pengaruh Pengetahuan Ekologis, Kemauan Membayar Lebih, dan Kesadaran Lingkungan Terhadap Keputusan Konsumen Dalam Membeli Produk Organik. Ilmu Manajemen Dan Akuntansi Terapan (JIMAT), 8(1). https://doi.org/https://doi.org/10.35446/ dayasaing.v4i2.246

Azis, A. D. Y. (2016). Neraca Ketersediaan Pupuk; Perbaikan Sistim Distribusi Dan Efisiensi Penggunaannya Untuk Mendukung Program " Pajale ." Prosiding Seminar Nasional Lahan Basah Tahun 2016.

Badan Pusat Statistik. (2020). Potret Sensus Penduduk 2020. https:// bps.go.id/publication/download.html?nrbvfeve=NjE2OThkYmQzNGIzOWI3MzE2M2Z 1NDlm\&xzmn=aHR0cHM6Ly93d3cuYnBzLmdvLmlkL3B1YmxpY2F0aW9uLzIwMjEvMTAvMTE vNjE2OThkYmQzNGIzOWI3MzE2M2Z1NDlmL3BkYi1pbmRvbmVzaWEtdHJpd3VsYW5hbiOyM DE3LTIwMjEuaHRtbA\%3D\%3D\&twoadfnoarfeauf=MjAyMSOxMSOwMiAxMjo 1MzowMg\%3D\% 3D. diakses tanggal 22 September 2021.

Badan Pusat Statistik. (2020). Indikator Pertanian 2020. https:/ / www.bps.go.id/publication/download.html?nrbvfeve=YTVmNjAyNWViOTBjODY1NjFj ZTQ0OWUw\&xzmn=aHR0cHM6Ly93d3cuYnBzLmdvLmlkL3B1YmxpY2F0aW9uLzIwMjAvMTE vMzAvYTVmNjAyNWViOTBjODY1NjFjZTQ0OWUwL2luZGlrYXRvci1wZXJOYW5pYW4tMjAxOS 
5odG1s\&twoadfnoarfeauf=MjAyMSOxMSOwMiAxMzoxMTozOA\%3D\%3D. diakses tanggal 22 September 2021

Badan Pusat Statistik. (2021). Kabupaten Timor Tengah Utara Dalam Angka 2021. https:/ / timortengahutarakab.bps.go.id/publication/download.html?nrbvfeve=OTZiNzUyZDZ hNTA5Y2IwNGYwNjRmYjE0\&xzmn=aHROcHM6Ly90aW1vcnRlbmdhaHVOYXJha2FiLmJwcy5 nby5pZC9wdWJsaWNhdGlvbi8yMDIxLzAyLzI2Lzk2Yjc1MmQ2YTUwOWNiMDRmMDY0ZmIxN C9rYWJ1cGF0ZW4tdGltb3ItdGVuZ2FoLXVOYXJhLWRhbGFtLWFuZ2thLTIwMjEuaHRtbA\%3 D\%3D\&twoadfnoarfeauf=MjAyMSOxMSOwMiAxMzozMzoyMA\%3D\%3D. diakses tanggal 22 September 2021

Badan Pusat Statistik. (2021). Produk Domestik Bruto Indonesia Triwulanan 2017-2021. https://bps.go.id/publication/download.html?nrbvfeve=MjEzOTk1Yzg4MTQyOGZ1ZjIwYTE4 Mj12\&xzmn=aHROcHM6Ly93d3cuYnBzLmdvLmlkL3B1YmxpY2FOaW9uLzIwMjEvMDEvMjEv MjEzOTk1Yzg4MTQyOGZIZjIwYTE4MjI2L3BvdHJldC1zZW5zdXMtcGVuZHVkdWstMjAyMC1t ZW51anUtc2FOdS1kYXRhLWtlcGVuZHVkdWthbi1pbmRvbmVzaWEuaHRtbA\%3D\%3D\&twoa dfnoarfeauf=MjAyMSOxMCOzMSAyMzowMzo0MQ\%3D\%3D. diakses tanggal 22 September 2021.

Christyanto, M., \& Mayulu, H. (2021). Pentingnya pembangunan pertanian dan pemberdayaan petani wilayah perbatasan dalam upaya mendukung ketahanan pangan nasional: Studi kasus di wilayah perbatasan Kalimantan. Journal of Tropical AgriFood, 3(1). https://doi.org/10.35941/jtaf.3.1.2021.5041.1-14

Damanik, I. P. N., \& Meilvis, E. T. (2020). Perilaku Komunikasi Petani dan Strategi Penguatan Kapasitas Mengakses Informasi Pada Era Revolusi Industri 4.0 di Kota Ambon. Jurnal Penyuluhan, 16(01).

Darwis, V., \& Supriyati, N. (2016). Subsidi Pupuk: Kebijakan, Pelaksanaan, dan Optimalisasi Pemanfaatannya. Analisis Kebijakan Pertanian, https://doi.org/10.21082/akp.v11n1.2013.45-60

Descartes, D., Harianto, H., \& Falatehan, F. (2021). Penyuluhan Pertanian dan Pengaruhnya terhadap Pendapatan Usahatani di Gapoktan Rorotan Jaya, Rorotan, Cilincing, Provinsi Dki Jakarta. Jurnal Ekonomi Pertanian Dan Agribisnis, 5(2), 390-403. https://doi.org/10.21776/ub.jepa.2021.005.02.10

Dwiastuti, R., Asmara, R., \& Rahayu, P. (2010). "Analisis Sikap Dan Norma Subyektif Sebagai Faktor Yang Mempengaruhi Keputusan Pembelian Petani Terhadap Pupuk Organik Kemasan." AGRISE: Agricultural Soci-Economics Journal, 10(2), 87-97.

Hakim, L., \& Saragih, R. (2019). PENGARUH CITRA MEREK, PERSEPSI HARGA DAN KUALITAS PRODUK TERHADAP KEPUTUSAN PEMBELIAN KONSUMEN NPK MUTIARA DI UD.BARELANG TANI JAYA BATAM. ECOBISMA (JURNAL EKONOMI, BISNIS DAN MANAJEMEN), 6(2). https://doi.org/10.36987/ecobi.v6i2.4

Indraningsih, K. S. (2016). Pengaruh Penyuluhan Terhadap Keputusan Petani dalam Adopsi Inovasi Teknologi Usahatani Terpadu. Jurnal Agro Ekonomi, 29(1). https://doi.org/10.21082/jae.v29n1.2011.1-24

Juanda,B. (2009). Ekonometrika Permodelan dan Pendugaan cetakan pertama: Februari 2012 Bogor: Penerbit IPB Press PT

Kementerian Keuangan. (2020). Apbn 2020. https://www.kemenkeu.go.id/apbn2020. diakses tanggal 21 September 2021

Mamondol, M. R., \& Sabe, F. (2016). Pengaruh Luas Lahan Terhadap Penerimaan, Biaya Produksi, Dan Pendapatan Usahatani Padi Sawah Di Desa Toinasa Kecamatan Pamona Barat. Envira, 1(2), 48-59. https://doi.org/10.31227/osf.io/pz7ne

Nasution, M. P., \& Wardana, A. (2020). ANALISIS PENGAMBILAN KEPUTUSAN PEMBELIAN PETANI DALAM MEMILIH BIBIT KELAPA SAWIT VARIETAS TENERA DI PERKEBUNAN RAKYAT. Juripol (Jurnal Institusi Politeknik Ganesha Medan), 3(2). https://doi.org/10.33395/juripol.v3i2.10839

Pangan, D. K. (2007). KEBIJAKAN UMUM KETAHANAN PANGAN 2006 - 2009. Jurnal Gizi Dan Pangan, 1(1). https://doi.org/10.25182/jgp.2006.1.1.57-63

Permana, H., Sativa, F., \& Nurfatiyah, P. (2018). Faktor-Faktor Yang Mempengaruhi Keputusan Petani Dalam Pemanfaatan Lahan Rawa Lebak Pada Usahatani Padi Sawah Di Desa Pasar Terusan Kecamatan Muara Bulian Kabupaten Batanghari. Jurnal Ilmiah Sosio-Ekonomika Bisnis, 19(1). https://doi.org/10.22437/jiseb.v19i1.4957

Pinem, L. J., \& Pratiwi, M. (2020). Faktor-Faktor Pendorong Petani Dalam Memilih Benih Kelapa Sawit (Elaeis guineensis) Bersertifikat Dan Nonsertifikat. AGRIMOR, 5(1). https://doi.org/10.32938/ag.v5i1.853

Prasetyo, K., Fariyanti, A., \& Suharno, S. (2019). Faktor Sosial Ekonomi Yang Mempengaruhi Keputusan Petani Mengikuti ProgramAsuransi Usahatani Padi (AUTP) di Kabupaten 
Indramayu Provinsi Jawa Barat. JURNAL AGRIBISAINS, https:/ / doi.org/10.30997/jagi.v5i1.1591

Setiawati. (2016). Faktor-Faktor yang Mempengaruhi Adopsi Inovasi Teknologi Padi Organik di Desa Telang Sari Kecamatan Tanjung Lago Kabupaten Banyuasin. Jurnal Triagro, 1(1).

Siallagan, J. O., Chalil, D., \& Jufri, M. (2014). Analisis Efisiensi Penggunaan Pupuk Bersubsidi pada Tanaman Padi Sawah. Journal on Social Economic of Agriculture and Agribusiness, 2(4), 1-10. https://jurnal.usu.ac.id/index.php/ceress/article/view/7849

Simamora, T. (2020). Peningkatan Kompetensi Peternak dan Keberlanjutan Usaha Sapi Potong di Desa Oebkim Kecamatan Bikomi Selatan Kabupaten Timor Tengah Utara. AGRIMOR, 5(2). https:/ / doi.org/ 10.32938/ag.v5i2.1007

Sipayung, B. P., \& Joka, U. (2021). Efek Multiplier Dana Desa di Masyarakat Tani Desa Perbatasan NKRI-RDTL Kabupaten Timor Tengah Utara. AGRIMOR, 6(1). https://doi.org/10.32938/ag.v6i1.1246

Syuhudi, M. I. (2020). DINAMIKA KEBANGSAAN MASYARAKAT PERBATASAN INDONESIA PAPUA NUGINI DI MUARA TAMI JAYAPURA. Al-Qalam, 26(2). https:/ /doi.org/10.31969/alq.v26i2.872

Tahoni, T. T., \& Mambur, Y. P. V. (2020). Peran Penyuluh Pertanian dalam Peningkatan Produktivitas Kelompok Tani di Desa Oesoko Kecamatan Insana Utara. AGRIMOR, 5(4). https://doi.org/10.32938/ag.v5i4.1181

Widiyanti, V. E. (2016). SIKAP PETANI TERHADAP KEBIJAKAN SUBSIDI PUPUK DI KECAMATAN CAWAS KABUPATEN KLATEN. Agrista: Jurnal Ilmiah Mahasiswa Agribisnis UNS, 4(3). 